\title{
Poesia, humanização e ensino da Língua Inglesa
}

\author{
Leonardo Jovelino Almeida de Lima ${ }^{\mathrm{i}}$
}

\section{RESUMO}

Este artigo ensaístico pretende apresentar uma discussão em torno do trabalho com a poesia nas aulas de língua inglesa, enfatizando o caráter humanizador desse gênero literário. Experiências que enfocam a poesia nos contextos atuais de ensino mostram como ela carece de estar presente em atividades que proporcionem seus benefícios, os quais não podem ser unicamente em prol de questões gramaticais ou estruturais da língua. Assim, são reunidos argumentos que definem a poesia e explicitam seu papel na sociedade onde ela circula. Em seguida, parte-se para reflexões sobre a característica humanizadora de tal gênero literário, baseando-se, precipuamente, nas considerações de Candido (2011). Por fim, considera-se defender a relevância da poesia e seu papel humanizador na sala de aula de língua inglesa.

Palavras-chave: Poesia; Humanização; Ensino de Língua Inglesa.

\begin{abstract}
This essay aims to present a discussion about the work with poetry in English language classes, emphasizing the humanizing character of this literary genre. Experiences which focus on poetry in current educational contexts reveal how it needs to be present in activities that provide its benefits, which cannot be solely in favor of grammatical or structural issues of the language. Thus, arguments that define poetry and explain its role in the society where it circulates are reunited. Secondly, it reflects on the humanizing characteristic of such a literary genre, based mainly on the words of Candido (2011). Finally, it considers defending the relevance of poetry and its humanizing role in the English language class.
\end{abstract}

Keywords: Poetry; Humanization; English Language Teaching.

\section{CONSIDERAÇÕES INICIAIS}

\footnotetext{
i Possui graduação em Letras com Habilitação em Língua Inglesa na Universidade Federal do Pará (2018) e Especialização em Literatura Inglesa pela Faculdade São Luis (2019). Mestrando do programa de Letras - Linguística da Universidade do Estado do Rio de Janeiro. Foi responsável pelo projeto de extensão universitária 'Playful: Proyecto Trilingue', que atuou no ensino da língua inglesa e espanhola para crianças e adolescentes residentes na comunidade do Fama, Outeiro, Pará. Atualmente é professor de língua inglesa do fundamental I. ORCID: https://orcid.org/0000-0001-9299-3182 / E-mail: leolimamat@hotmail.com
} 
O contato com os textos literários, em suas diversas manifestações (como poesias, contos, crônicas, romances, entre outras), proporciona aos leitores significativas formas de ver e perceber o mundo, seja através do estímulo à criatividade e imaginação, ou seja, por meio da leitura de diferentes histórias, fatos, situações, reflexões, culturas etc., ou até mesmo pela possibilidade de promoção do senso estético e crítico. Essas significativas formas atribuem à literatura uma característica humanizadora (CANDIDO, 2011), isto é, característica que estimula o leitor ao desenvolvimento da criticidade, reflexão e atuação no meio social.

Todavia, ao considerarmos o uso da literatura nos ambientes pedagógicos, questionamentos podem surgir, sobretudo, quanto aos possíveis benefícios (ou entraves) ocasionados ao ensino e à aprendizagem. A título de exemplificação, cito o seguinte: no caso das aulas de línguas adicionais, especificamente, no presente ensaio, a língua inglesa, o trabalho com a literatura se mostraria enriquecedor ou apenas se tornaria uma ferramenta descontextualizada nas mãos do professor e dos alunos? É claro que, para responder essa pergunta, muitos fatores devem ser avaliados: os contextos e os instrumentos disponíveis, os objetivos de aprendizagem e as necessidades dos alunos. Contudo, norteando-se pelas experiências do presente autor na condição de professor de língua inglesa que constantemente tem buscado utilizar-se da literatura durante as aulas. Nesse sentido, este artigo ensaístico parte da perspectiva de que o trabalho com a poesia proporciona benefícios tanto para o próprio professor quanto para os alunos, tornandose relevante para a aprendizagem da língua adicional. Em vista disso, assumo como objetivo apresentar uma discussão em torno do trabalho com a poesia nas aulas de língua adicional, a saber, a língua inglesa, enfatizando, pois, o caráter humanizador enraizado nesse gênero literário.

Ao nos atentarmos para os contextos que envolvem a poesia no ensino e na aprendizagem de línguas, seja ela materna ou adicional, percebemos uma expressiva escassez quanto ao seu uso em sala de aula. Além da existência de crenças que contribuem para essa escassez, há alunos e professores que não percebem a significância das poesias para a aquisição da língua-alvo. Pilati (2017) nos apresenta um pouco sobre a realidade brasileira no que se refere ao trabalho com a literatura no ensino médio e superior. De acordo com esse autor, basicamente não existem práticas 
pedagógicas que enfatizem os benefícios reais das produções literárias, tanto em prosa quanto em verso. Quando se trata dos poemas, expressões que carregam a poesia normalmente são evitadas nas aulas de línguas pela falta de conhecimento e preparação dos professores. Assim, os alunos entendem essas produções como inviáveis e difíceis de ler e interpretar.

Para a consecução do objetivo supracitado, parto das concepções de poesia e de como esse gênero literário apresenta uma função social que, mesmo sendo desacreditada por muitos e perante uma realidade que não favorece a prática da leitura literária, ela pode ser visualizada desde as escolhas e expressões do poeta até o contato final da poesia com o leitor. Em seguida, discuto a característica humanizadora da literatura, especificamente da poesia, tendo como norte as ideias de Candido (2011). E, por fim, proponho considerações sobre como a poesia, enfatizada pelo seu caráter humanizador, pode ser efetivamente trabalhada nas aulas de língua inglesa. Para tanto, destaco como a literatura, quando adequadamente utilizada, pode romper com padrões tradicionais de ensino e favorecer a aprendizagem contextualizada, pautada na dinamicidade e não centrada no professor.

\section{POESIA, SUA FUNÇÃo SOCIAL E SEU CARÁtER HUMANIZADOR}

Antes de adentrar no âmbito humanizador da poesia, considero primordial discutir como esse gênero literário pode ser conceituado. A utilização da palavra “conceituar" pode exigir que pensemos em uma definição fechada e precisa. Contudo, acredito nas diferentes discussões em torno do que é o gênero literário poesia, dificultando, dessa forma, a atribuição de um conceito fixo. Assim, assumo aqui uma tentativa de conceituação da poesia; tentativa essa que nos ajudará a compreender sua própria relevância para a sociedade e também o seu caráter humanizador. Tentar conceituar esse gênero literário assim como compreender sua função social motiva-nos a levantar, a priori, dois questionamentos: o que vem a ser poesia? E para que ela, de fato, serve? Em vista disso, atentar-me-ei, primariamente, ao primeiro questionamento.

Moisés (2012), na intenção de atribuir um conceito à poesia e, portanto, diferenciar esta da prosa, parte (ousadamente, permito-me dizer) de uma equação básica 
que expressa o todo: $e u+n \tilde{a} o \mathrm{eu}$, sendo esse todo compreendido como o real espiritual, o real da matéria e o ser, ou seja, a pessoa que pensa e sente. Dessa forma, enquanto a poesia tem por objeto o $\mathrm{eu}$, ou seja, o real espiritual, a prosa, por outro lado, focaliza-se no não eu, ou no real da matéria.

As palavras de Moisés (2012) direcionam nosso olhar para dentro se quisermos de fato entender o que é poesia, visto que o real da matéria, tudo aquilo que é externo, entendido como englobado no não eu da equação, fica a cargo da prosa. Todavia, cabe uma pergunta: se a poesia corresponde ao $e u$ na equação, esta não estaria incongruente dado que o não eu incorpora ou está incorporado no eu? Afinal, a poesia somente existe porque o real das matérias, o real físico, o não eu, também existe. A poesia se manifesta através das palavras e são as próprias palavras que nomeiam o mundo, ou seja, o não eu. Por sorte, encontro a resposta para essa pergunta nas palavras de Moisés (2012): o autor explana que uma carga do não eu pode aparecer na poesia, mas, compreende-se que ela passa por uma transformação provocada pelas vivências de quem escreve, do poeta. "O mundo subjetivo e o objetivo aderem-se, imbricam-se, formando uma só entidade, subjetivo-objetiva, com forçosa predominância do primeiro" (MOISÉS, 2012, p. 69). Em resumo, o que Moisés nos apresenta é uma relevante definição de poesia: ela é expressão do $e u$ e, sendo a palavra signo por excelência, podemos entender que a poesia é a expressão do $e u$ através da palavra (MOISÉS, 2012).

A conceituação acima apresentada acende-me uma segunda pergunta igualmente interessante: sendo a poesia uma expressão do eu pela palavra, podemos dizer que toda manifestação da palavra é poesia? Minhas experiências enquanto leitor do gênero poético “anseiam” pela negação. Contudo, não assumo aqui que existam palavras poéticas e não poéticas. Acredito que a palavra, enquanto presença marcante no mundo, precisa passar pela peneira do $e u$ do poeta - do eu que se esconde nas entranhas do ser que vive, pensa e sente - para que, então, possa se transformar em poesia. É justamente nessa passagem de dentro para fora, do eu para o não eu, que a poesia acontece; e suas palavras, as palavras que passaram pelo crivo do poeta, adquirem uma nova roupagem. Enfatizo que essa nova roupagem se apresenta fortemente através da linguagem metafórica, conforme explica Shelley (2008, p. 80): 
palavras que as representam se tornam, pelo tempo, sinais para partes ou tipos de pensamentos, ao invés de quadros de pensamentos completos; e então, se novos poetas não se erguerem para criar inéditas associações que antes estavam desorganizadas, a linguagem morrerá para todos os nobres propósitos do relacionando humano.

Compreendo, dessa forma, como a linguagem da poesia acaba por ser essencialmente metafórica. Sem essa característica, a poesia, possivelmente, nada terá a oferecer ao mundo senão um conjunto de palavras que pode, muito bem, pertencer somente ao âmbito do não eu. A poesia deve vir de dentro do poeta e é nesse vir de dentro que ela se torna efetivamente poesia. Isso nos revela outra importante característica da poesia, pois, sendo ela movida pela linguagem metafórica, em minha visão, sua estrutura não é o que, essencialmente, a define. Podemos encontrar a poesia em textos versificados e metrificados assim como em textos produzidos estruturalmente em prosa. Fato esse que nos aponta para as poesias em prosa ou para as prosas poéticas: textos produzidos em um estilo livre, direto e não versificado, cujas palavras carregam a chama da poesia. Ao lermos esses textos, somos altamente impactados pela polivalência das suas palavras. É como levanta Terra (2018): a poesia, para ser poesia, não necessita se manifestar em textos com rimas ou em versos, nem precisa ter uma forma fixa determinada. Em suma, um texto pode ser escrito em prosa e ser poético assim como apresentar rimas, versos e forma fixa e não ser poesia.

À luz do exposto, podemos acreditar, então, que a poesia, enquanto manifestação por meio das palavras, pode não ser o que deveria, inicialmente, ser. A palavra tem sentido próprio convencionalmente aceito, porém, enquanto poesia, esse sentido se abstrai e ganha nova roupagem e um novo emprego. Mesmo que, para Carlos Drummond de Andrade, "[...] uma pedra no meio do caminho" (ANDRADE, 2015, p. 20) seja apenas uma pedra no meio do caminho, para muitos leitores, o sentido da pedra nada tem a ver com o que foi inicialmente convencionado. Além disso, a relação da poesia com as palavras nos remete ao conceito do poema, sendo este, portanto, "a soma de significantes e significados mediante os quais a poesia procura comunicar-se" (MOISÉS, 2012, p. 72).

Mesmo que muitas vezes poesia e poema sejam compreendidos como um mesmo gênero, assumo, piamente, que existam significativas diferenciações. Trago para essa discussão as palavras de Paz (1982, p. 17), que entende o poema como "organismo verbal que contém, suscita ou emite poesia”. Assim sendo, poema é a produção literária 
escrita ou criação artística por meio da qual o poeta transmite seus sentimentos, emoções, suas intenções, necessidades etc., ou seja, transmite a poesia. Ademais, vemos como os conteúdos que movem a própria poesia, por meio dos poemas, são também essenciais para a discussão sobre nossa intenção de conceituação, visto que esses conteúdos são fortemente baseados na subjetividade, na particularidade e no egocentrismo.

Podemos dizer que as poesias estão manifestadas nas produções que expressam as confissões, as emoções, as interioridades e as profundezas do $e u$; sendo, portanto, carregadas de julgamentos subjetivos, alegrias, tristezas, interesses, admirações etc. Isso significa dizer que a poesia não tem a intenção apenas de expressar o amor, apesar de esse sentimento estar presente em uma abundância de produções poéticas. A poesia, norteada pela subjetividade, pela particularidade e pelo egocentrismo, expressa qualquer categoria de sentimento do poeta: amor, ódio, raiva, inveja, alegria, humor, esperança, frustração e outros.

Torna-se relevante explicitar que o exemplo supracitado sobre a pedra de Carlos Drummond de Andrade evidencia a relevância do leitor para a própria conceituação da poesia. Afinal, o que seria do apreciado sem o ser apreciador? Apenas um conjunto de significados e significantes transformados pelo $e u$ do poeta em palavras polivalentes, metafóricas, à espera de um deslumbramento? Para uma discussão a esse respeito, revisito as palavras de Moisés (2012, p. 74):

\footnotetext{
Quanto a poesia que ficou registrada nos poemas, surge-nos por intermédio da leitura, o que equivale a dizer que damos vida, cada qual a seu modo e quantas vezes quiser, à poesia que os poemas deflagram. Significa que a poesia está em nós e não no poema, o que nos torna poetas embora não criadores do poema.
}

Nesse mesmo percurso, Terra (2018), ao definir o conceito de poesia, singelamente aponta para a relevância do próprio leitor. Para o autor, a poesia, ao se direcionar ao íntimo de cada leitor, torna-se uma "forma de manifestar os grandes temas que sempre preocuparam o ser humano, como o amor, a morte, o medo etc." (TERRA, 2018, p. 83). Moisés também explica que a poesia pode ser defendida como uma manifestação, "por meio da palavra, de uma voz humana quase sempre individual, por vezes coletiva ou anônima, que para sobreviver ou até para existir precisa encontrar ouvidos humanos que a propaguem e multipliquem" (2019, p. 15). 
As palavras de Moisés (2019) e de Terra (2018) são, em minha opinião, fortemente ousadas. Contudo, elas podem ser bem aceitas se quisermos, de fato, compreender como a poesia pode ser realmente conceituada. A poesia está nas palavras que vieram de dentro do poeta e, assim, passaram por uma nova roupagem para que, já aqui fora, possam ser apreciadas por aqueles que igualmente apresentam um eu carregado de sentimentos, emoções, necessidades e interesses. Em virtude disso, assumo que a poesia só se faz presente porque tem um espectador, um apreciador, que também motiva a sua manifestação. Em suma, o poeta, ao expressar a sua poesia, o faz na intenção de atingir alguém com suas palavras; de motivar uma reflexão no outro; de levantar uma interpretação, ou até indagação, e de chamar o leitor para sentir junto. Atrevo-me a dizer que ninguém produz poesia para que esta fique escondida. Toda poesia precisa ser apreciada. Caso contrário, qual a necessidade de tirá-la de dentro de si? A poesia é como uma dança: alguém que gosta de dançar (poeta) convida (por meio das palavras) um parceiro para tal ação (leitor); e é justamente na coerência dos movimentos, no ritmo, na musicalidade, na sincronização, que a beleza da dança (poesia) acontece. Algumas danças podem ser realizadas sem um parceiro, mas penso que essas não proporcionam a mesma formosura.

A relevância do leitor para a discussão sobre a poesia nos direciona para o segundo questionamento apresentado no início deste tópico: para que ela, de fato, serve? A resposta para essa pergunta pode ser ainda mais desafiadora de se alcançar, pois muitas controvérsias giram em torno da (não?) importância da poesia para as pessoas e para a sociedade. Todavia, neste ensaio, acredito que a poesia, assim como qualquer outra manifestação artístico-literária, apresenta, sim, uma função social significativamente positiva. E, para fundamentar tal crença, trago para a discussão as palavras de Eliot (1991), Shelley (2008), Todorov (2009), Pilati (2017), Pinheiro (2018) e Moisés (2019).

Eliot (1991), em seu ensaio sobre "A função social da poesia", presente no livro De poesia e poetas, afirma que o poeta, quando exprime os seus sentimentos, acaba exprimindo, igualmente, o que as outras pessoas sentem. Assim, quando um leitor entra em contato com a poesia, ele se torna consciente daquilo que ele também está sentindo. Em outras palavras, o poeta suscita, ensina as pessoas a olharem para dentro e a perceberem e aprenderem algo sobre si mesmas. A poesia pode despertar nos leitores 
novos sentimentos e emoções, ainda não experimentados ou até mesmo não percebidos, afinal, "o excêntrico modo de ver, ensinado pela poesia, incita-nos a encarar o objeto (coisa ou ideia) sobejamente visto, como se nunca o tivéssemos visto antes" (MOISÉS, 2019, p. 23).

Já Shelley (2008), em um tom sutilmente poético para falar sobre a própria poesia, explica que:

\begin{abstract}
A poesia ergue o véu da beleza oculta do mundo e torna familiar objetos como se não fossem familiares; reproduz tudo o que representa e as interpretações revestidas nesta luz Elísia permanecem, desde então nas mentes daqueles que, uma vez, as contemplaram como memoriais daquele conteúdo gentil e exaltado, que se estende sobre todos os pensamentos e ações com as quais coexistes (SHELLEY, 2008, p. 89).
\end{abstract}

O que os supracitados autores nos exprimem é que a poesia apresenta uma função de favorecer o reconhecimento e o autoconhecimento. O poeta, quando produz a poesia, expressa sentimentos e emoções que também correspondem a sentimentos e emoções presentes nas outras pessoas. Em virtude disso, quando entramos em contato com a poesia, reconhecemos esses sentimentos e emoções, não somente nela, mas também em nós, e isso, por si só, diz muito sobre nós mesmos. Através da poesia, vemos que não estamos sozinhos no mundo; aprendemos a perceber sensibilidades impregnadas que influenciam fortemente nossas ações do cotidiano e a entender que o outro também as apresenta; nos vemos como seres sociais que compartilham e também se comunicam. Em resumo, a poesia nos ajuda a compreender quem somos, bem como aguça a percepção do outro.

É como explica Todorov (2009) ao falar da literatura. Para o autor, a literatura pode nos ajudar quando estamos, por exemplo, deprimidos, tornando-nos mais próximos dos nossos pares. Além disso, por meio dos textos literários, podemos compreender melhor o mundo que nos rodeia, transformando-nos a partir de dentro. Nesse mesmo caminho, Pilati (2017, p. 16) expõe que a poesia

[...] participa efetivamente das nossas práticas vitais, ou seja, das nossas experiências do cotidiano que nos formam e nos fazem viver, das atividades que são necessárias para a produção de nós mesmos como seres humanos, seres sociais. 
Apesar das considerações de Todorov (2009) e Pilati (2017) serem mais objetivas se comparadas às de Elliot (1991) e Shelley (2008), elas resumem eficientemente como a poesia tem um poder transformador que começa internamente e que pode se refletir externamente, em nossa convivência. No entanto, as citações apresentadas podem erroneamente atribuir à poesia uma característica remediadora e, ouso dizer, até salvadora. Acredito sim, no poder transformador da poesia, mas, para de fato entendermos a sua função social, pensemos em um andamento mais singelo e em passos mais curtos em direção a uma possível transformação. A literatura, especificamente a poesia, não se apresenta como uma solução para todos os males sociais. Mas, como já dito anteriormente, ela nos ajuda na compreensão de nós mesmos, na percepção do outro enquanto seres também sociais, tornando-nos, pois, mais humanos; já que "o modo como o poeta diz - e o que diz - ou comunica sua experiência permite um encontro íntimo entre o leitor-obra que aguçará suas emoções e sua sensibilidade" (PINHEIRO, 2018, p. 17), o que acaba, dessa forma, refletindo no cotidiano desse leitor. Aceito, portanto, que a literatura apresenta um caráter fortemente humanizador, conforme será melhor explorado adiante.

Para falar sobre o caráter humanizador atribuído à poesia, este artigo ensaístico parte das concepções de Antonio Candido que, em seu texto intitulado "O direito à literatura", presente no livro Vários escritos, nos diz que humanização se refere ao

[...] processo que confirma no homem aqueles traços que reputamos essenciais, como o exercício da reflexão, a aquisição do saber, a boa disposição para com o próximo, o afinamento das emoções, a capacidade de penetrar nos problemas da vida, o senso de beleza, a percepção da complexidade do mundo e dos seres, o cultivo do humor (CANDIDO, 2011, p. 182).

O que Candido nos aponta é que, ao considerarmos a função social da literatura, percebemos como ela também é nutrida de um cunho humanizador, que nos permite explorar e exercer aspectos que são essencialmente humanos. Quando entramos em contato com a literatura, por exemplo, nos despertamos para questões não somente estéticas, mas também reflexivas; experienciamos o conhecimento dos nossos pares assim como o autoconhecimento; acendemos emoções e sentimentos; conhecemos, pois, mais sobre questões culturais e sobre o mundo; apreendemos diferentes necessidades e 
intenções; entre outras coisas que, conforme podemos notar, nos fazem reafirmar nossa condição de seres humanos.

Destarte, podemos vislumbrar como essa característica humanizadora é fortemente marcada na poesia, visto que ela "fortalece a faculdade que é o órgão da natureza moral do homem, da mesma maneira que o exercício fortalece o músculo" (SHELLEY, 2008, p. 90); “compele-nos a sentir aquilo que percebemos e a imaginar aquilo que sabemos" (SHELLEY, 2008, p. 118); "nos ensina a sentir melhor o mundo, a dar atenção às coisas que não têm importância" (PINHEIRO, 2018, p. 124); nos fala sobre o mundo social, que é "[...] o mundo das relações humanas, o mundo construído pelo trabalho dos homens, é o tecido comunitário onde a vida humana se desenvolve" (PILATI, 2017, p. 30); “produz diferença na fala, na sensibilidade, nas vidas de todos os integrantes de uma sociedade, de todos os membros de uma comunidade, de todo um povo" (ELIOT, 1991, p. 33); "nos ensina a ver como se víssemos pela primeira vez" (MOISÉS, 2019, p. 17). Considerando todos esses argumentos, podemos compreender como a poesia "é práxis vital porque, assim como as outras artes, é capaz de refletir e de produzir a humanidade dos seres humanos" (PILATI, 2017, p. 16).

Perceber esse caráter humanizador da poesia, e demais produções literárias, pode se tornar uma ferramenta positiva para o trabalho nos ambientes onde a própria literatura não é usufruída em sua plenitude, considerada em todos os seus recursos. Conforme vimos no item introdutório deste ensaio, a poesia é normalmente evitada nos contextos pedagógicos por conta de falsas crenças acerca desse gênero. Ao enfatizarmos o ensino da língua inglesa, minhas experiências como antigo aluno e atual docente têm me mostrado como a poesia necessita ganhar mais espaço na sala de aula. Por conta disso, cabe aqui outro questionamento: trabalhar a poesia e sua característica humanizadora não seria enriquecedor para as aulas de línguas adicionais justamente por permitir que tanto o professor quanto o aluno exercitem questões que estão além da própria língua? Como sabemos, aprender, por exemplo, a língua inglesa não diz respeito a apenas adquirir a língua, uma vez que outros fatores também estão envolvidos nesse processo de aprendizagem, como questões culturais e históricas, estímulo à interpretação, reflexões etc. Pensando nesse questionamento, no tópico a seguir, discutirei como a poesia pode ser trabalhada nas aulas de língua inglesa, ressaltando, pois, seu cunho humanizador. 


\section{POESIA E HUMANIZAÇÃO NO ENSINO DA LÍNGUA INGLESA}

Trabalhar com a poesia nas aulas de língua inglesa (assim como nas de outras línguas) requer a utilização desse gênero literário em sua plenitude, levando em consideração não somente os aspectos linguísticos e estruturais como também aqueles que, mesmo fortemente presentes na literatura, não estão tão visíveis e, portanto, necessitam ser apresentados e estimulados pelo professor. Considerar a natureza humanizadora da poesia nas aulas pode demandar um efetivo usufruto da leitura, permitindo, dessa forma, que os alunos possam não somente aprender a língua-alvo como também ter um contato mais aproximado e, ouso dizer, íntimo com esta. Todavia, devemos ter em mente que trabalhar com a literatura e seu caráter humanizador não é uma tarefa tão simples. Decisões relevantes precisam ser tomadas, principalmente pelo professor, que vão desde a escolha adequada dos textos literários até a permissão de uma aula mais participativa e dinâmica, na qual os alunos possam ter mais possibilidades de expressão e, dessa forma, o próprio professor não seja o foco.

McCloskey e Stack (1996) nos fornecem dicas de como o trabalho com a literatura nas aulas de língua inglesa pode ser iniciado. Segundo os autores, o professor deve se atentar para três fatores: a) os textos literários que serão utilizados devem concordar com os interesses dos alunos e suas necessidades; b) os textos devem ser linguisticamente acessíveis aos alunos, ou seja, devem corresponder ao nível de conhecimento dos mesmos em relação ao inglês; e c) os textos devem apresentar uma relevância cultural.

As dicas dos autores supracitados podem se apresentar no campo da obviedade. Porém, se não seguidas em plenitude podem ajudar a reforçar o contexto apresentado por Pilati (2017) no item introdutório deste ensaio; contexto esse que pode ser resumido em docentes não preparados para o uso da poesia e alunos que tendem a evitá-la por acreditarem que esse gênero literário seja difícil de ler e interpretar. Toda aula, seja ela de línguas ou não, deve começar por um apropriado planejamento e, no caso do trabalho com a poesia, a escolha adequada dos textos (dos poemas) torna-se fator primordial para o alcance eficaz dos objetivos de aprendizagem. 
O trabalho com a poesia também requer que a aprendizagem da língua inglesa seja compreendida como um processo e, para isso, cabe ao professor a organização da aula em três momentos que, neste ensaio, chamarei de: "antes da poesia", "durante a poesia" e "depois da poesia". Cada um desses momentos torna-se essencial, pois permite que não somente a poesia seja o foco da aula, mas também tudo o que ela, direta ou indiretamente, carrega consigo.

O momento que corresponde a "antes da poesia" deve contribuir para que os alunos sejam preparados para a leitura e interpretação, ou seja, ele deve anteceder o contato com a poesia. Cabe, portanto, a ativação de conhecimentos prévios relacionados aos conteúdos da poesia, as discussões sobre os pontos que serão tratados, e a possibilidades de os alunos poderem associar esses pontos com as suas vivências e experiências pessoais. Quando os alunos se preparam para a leitura da poesia, mais familiares eles se tornam com ela e significativas interpretações podem surgir. Além disso, mesmo que os poemas sejam produzidos na língua inglesa, esse primeiro momento possivelmente ajudará na compreensão dos alunos, permitindo-lhes antever assuntos tratados e inferir significados de palavras ou expressões, por exemplo.

Uma expressiva forma de o professor introduzir o trabalho com a poesia com seus alunos pode ser através do uso de diferentes gêneros textuais, não somente o poema, que também podem carregar a poesia. Partindo das ideias de Moisés (2019, p. 283):

\begin{abstract}
A poesia tem sido amada e reconhecida, desde a origem, como a essência de todas as artes, a substância imprescindível que alimenta, na verdade, todas as manifestações do espírito humano. Mas é também a mais modesta, a mais apagada dessas manifestações: sua repercussão é inversamente proporcional à importância que nossa cultura atribui. Por isso desde sempre, a velha arte de aedos não passa despercebida quando ganha apoio da música, da dança e do teatro.
\end{abstract}

Assumimos que a poesia, quando apoiada em outras manifestações artísticas, pode tornar as aulas mais interessantes e chamativas, contribuindo, pois, para a quebra da errônea crença associada à inviabilidade desse gênero literário que permeia entre os alunos. A música, os filmes, as danças, por exemplo, sendo gêneros fortemente difundidos entre os jovens e adultos atualmente, podem se revelar como grandes 
condutores da poesia. Logo, por que não os utilizar em sala de aula? Por que não trabalhar a poesia e sua humanização através das músicas, dos filmes ou da dança?

Franco (2017), em um trabalho com as obras de William Shakespeare, durante as aulas de inglês com alunos do Ensino Médio, utilizou-se do filme "Ten things I hate about you", de 1999. Em um primeiro momento, os alunos assistiram ao filme, depois foram guiados a discutirem sobre os tópicos principais: contextos históricos e culturais, personagens etc. Em um momento posterior, debateu-se sobre as definições de poesia, poema e soneto, o que levantou discussões a respeito de temas relacionados a sentimentos pessoais. Essas atividades levaram os alunos ao trabalho de leitura e interpretação (com ajuda também de estratégias, como: percepção dos cognatos e das palavras conhecidas, e análise dos prefixos e sufixos) do poema "Dez coisas que eu odeio em você", apresentado no filme de 1999, e do soneto 116, de Shakespeare.

Franco (2017) anuncia que as atividades se mostraram produtivas e satisfatórias, e os alunos estavam de fato empenhados em realizá-las. Ademais, as atividades permitiram que o professor pudesse estimular os alunos a explorarem a imaginação e os aspectos culturais, linguísticos e artísticos dos poemas. Conforme podemos notar, o uso de outros recursos em um momento anterior à leitura da poesia, além de chamar a atenção dos alunos, aproximou-os desse texto literário, possibilitando o trabalho não somente com questões voltadas para a aprendizagem da língua inglesa, mas também para aspectos humanizadores da literatura, como: o estímulo a discussões de questões socioculturais e históricas, as reflexões, a imaginação, etc.

O momento que corresponde a "durante a poesia" deve permitir que os alunos possam tirar o máximo proveito da poesia durante a leitura e interpretação, considerando questões não somente relacionadas à aprendizagem da língua inglesa, mas também ao caráter humanizador da literatura. Dessa forma, o professor, ao apresentar a poesia aos alunos, pode, inicialmente, trabalhar a interpretação desta, recorrendo a estratégias que contribuam para uma adequada leitura. Franco (2017) já nos apresentou acima algumas dessas estratégias (observar os cognatos, as palavras conhecidas e realizar análise dos prefixos e sufixos). ${ }^{1}$ Contudo, outras também podem se fazer necessárias, como, por exemplo, discutir conceitos-chave, que contribuem para que os alunos possam perceber as palavras ou expressões que mais se repetem na poesia, compreendendo, portanto, como elas podem ajudar na interpretação do texto; perceber 
elementos tipográficos, como o título, o autor, a estrutura da poesia etc., visto que cada elemento tem uma finalidade específica e, assim, podem contribuir para a compreensão; inferir significados de palavras ou expressões, sendo essa inferência motivada por conhecimentos que os alunos já possuem ou pelo próprio contexto da poesia (explicitando, pois, a relevância da realização do momento “antes da poesia”); entre outras estratégias que o professor considerar relevantes.

Não podemos descartar também a relevância do trabalho colaborativo durante a leitura e interpretação da poesia. Devemos ter em mente que o trabalho na sala de aula, além de exigir uma compreensão da aprendizagem como um processo, deve também exigir a percepção de que o conhecimento é construído entre os alunos e o professor. Dessa forma, entendo que a prática colaborativa se mostra imperativa para o trabalho com a literatura, especificamente com a poesia, durante as aulas de língua inglesa. Um bom exemplo dessa leitura e interpretação colaborativa pode ser constatado na pesquisa de Lima (2021). Ao trabalhar com o gênero poesia em uma turma de língua inglesa do quarto ano do Ensino Fundamental, o professor apresentou e estimulou a discussão e interpretação do seguinte poema com os alunos:

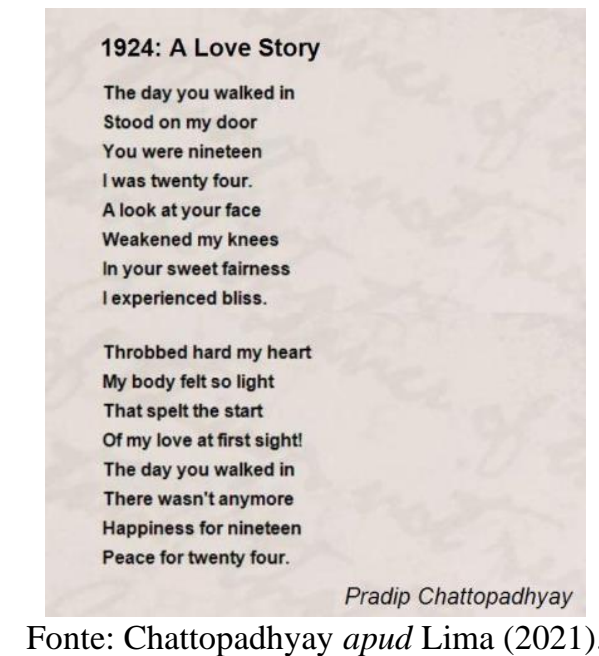

Ao se atentarem para o título, os alunos identificaram as palavras love e story e entenderam que o poema fala sobre uma história amor. Perguntas foram feitas aos alunos na intenção de motivar o conhecimento prévio deles e facilitar a leitura e interpretação, como, por exemplo: o que vocês entendem por "história de amor"? Com esse título, o que vocês esperam encontrar na poesia? Vocês perceberam que o título da 
poesia começa com os números 1924 ? O que esses números podem significar? Essa última pergunta levantada,

[...] foi somente respondida por uma aluna que, por apresentar uma interpretação diferente sobre os números 1924, causou uma significativa surpresa no professor (que acreditava que esse número correspondia ao ano em que a história de amor havia acontecido). Segundo a aluna, como a poesia evidenciava uma história de amor, o número 1924 poderia representar a junção das idades dos personagens (19 anos e 24 anos). Ela havia chegado a essa conclusão, pois havia lido os versos "You were nineteen" e "I was twenty four" (LIMA, 2021, p. 1197).

Conforme podemos observar, a leitura de forma colaborativa da poesia 1924: $a$ love story permitiu a expressão de opiniões, pontos de vistas e discussões dos alunos e dos mesmos com o professor, contribuindo, assim, para uma aula mais dinâmica e participativa. Essas atividades ofereceram um modo mais significativo de aprendizagem, permitindo a construção do conhecimento e favorecendo também o caráter humanizador da poesia. Outro significativo exemplo de como a construção do conhecimento através do uso da poesia nas aulas de língua inglesa pode acontecer em sala de aula também é dado por Lima (2021) ao trabalhar com o seguinte poema concreto na mesma turma do quarto ano, anteriormente citada:

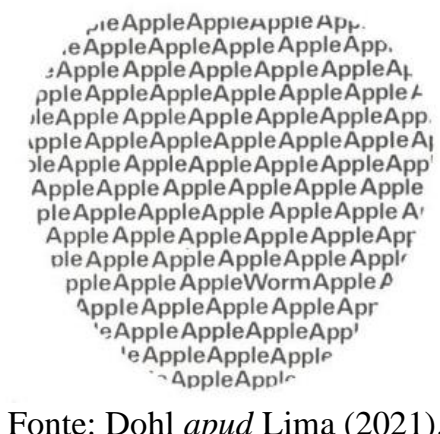

A forma do texto ocasionada pela junção planejada das várias palavras apple contribuiu para que os alunos compreendessem que o poema representava uma maçã. Todavia, ao notarem a palavra worm, que aparece sozinha entre o emaranhado de palavras apple no poema, os alunos não souberam dizer seu significado. Dessa forma:

O professor, ao ver que os alunos não sabiam o significado da palavra worm e, assim, não entendiam o motivo de ela estar presente na poesia, pediu para que eles tentassem pensar na imagem que a poesia estava apresentando: tudo que tinha a palavra apple representada uma maçã e entre essas palavras, 
aparecia a worm, ou seja, a representação de algo que estava na maçã. Dito isso, os alunos foram perguntados: o que pode, por exemplo, estar em uma maçã? Um aluno respondeu que worm poderia significar semente em português. Todavia, outro aluno argumentou que não poderia ser esse o significado uma vez que a palavra worm aparecia apenas uma vez na poesia e que uma maçã tem mais de uma semente. Após algumas reflexões e discussões, os alunos concluíram que worm só poderia significar minhoca, justamente pela ideia que eles tinham de uma minhoca saindo de uma maçã (LIMA, 2021, p. 1200).

Do relato de Lima (2021), pontuo dois importantes aspectos: o primeiro corresponde à versatilidade que podemos atribuir ao gênero literário em questão. Em outras palavras, além de podermos considerar a poesia em diferentes manifestações artísticas, conforme já discutido, também podemos adotar que a poesia se apresenta em diferentes formas, estruturas e conteúdos. $\mathrm{O}$ uso do poema concreto é um bom exemplo disso, uma vez que ele apela para a forma e a imagem. Essas diferentes formas, estruturas e conteúdos podem ser levadas para as aulas de língua inglesa como um modo de apresentar aos alunos a versatilidade da poesia e, portanto, tornar essas aulas mais atrativas. $\mathrm{O}$ segundo aspecto diz respeito à negociação de significados que ocorreu em sala. Esta negociação permitiu o exercício da reflexão e da discussão entre os alunos. Durante essa negociação, a opinião do outro, do par, foi recebida com expressiva importância.

Por fim, o momento que corresponde à "depois da poesia" deve estar nutrido de atividades que permitam aos alunos irem além dos conteúdos apresentados na poesia, relacionando, pois, os mesmos com situações, momentos, artefatos, problemas etc. da vida cotidiana e tornando, assim, a aprendizagem contextualizada e significativa. Em virtude disso, o professor pode incentivar discussões em sala de aula nas quais os alunos possam associar a poesia e seus conteúdos a experiências de cunho pessoal; conversar com os alunos sobre as intenções do poeta ao produzir a poesia; conversar com os alunos sobre aspectos culturais, sociais e históricos do local onde o poema foi produzido; relacionar a poesia trabalhada com outras que os estudantes possam conhecer; realizar atividades lúdicas que possam incitar a imaginação e a criatividade dos alunos; entre outras coisas.

Paula (2016) nos dá uma interessante proposta de como o professor pode ir além no trabalho com a poesia e oferecer aos alunos oportunidades para debater sobre questões culturais, sociais e históricas. Sua pesquisa nos mostra a aplicação de um 
projeto pedagógico em aulas de língua inglesa com alunos do oitavo ano do Ensino Fundamental, voltado para o contato com escritores afro-estadunidenses. Ao trabalhar, entre outros textos literários, com o poema Negro, de Langston Hughes, Paula (2016) nos mostra como o professor pode incentivar a realização de pesquisas sobre as temáticas apresentadas no poema, tais como: segregação racial nos Estados Unidos, África, Geórgia etc.; assim como pesquisas sobre a vida do poeta que, em minha visão, podem contribuir para a nossa interpretação do texto poético, uma vez que poderá nos ajudar a entender o motivo de ele ter escrito o que escreveu. Assim, segundo a autora, o trabalho com os textos literários permitiu que os alunos pudessem entrar em contato com a história de outro país e com temáticas relevantes para serem discutidas, como: discriminação e pobreza. Ademais, um ponto relevante levantado na pesquisa corresponde à mudança de postura que ocorreu entre os alunos em relação à questão da tolerância, através do entendimento de que diferimos, portanto, necessitamos de respeito. Esse ponto, conforme podemos observar, é a perfeita manifestação da função social da poesia e do seu caráter humanizador.

Cito novamente a pesquisa de Lima (2021), realizada com os alunos do quarto ano do Ensino Fundamental, para vermos como uma atividade lúdica pode ser praticada no momento posterior à leitura da poesia, tendo como finalidade o estímulo à imaginação e à criatividade dos alunos. Após a leitura do poema anteriormente citado, 1924: a love story, de Pradip Chattopadhyay, o professor de língua inglesa solicitou que os alunos fizessem um desenho de como eles interpretavam o poema, ou seja, como eles imaginavam que a história de amor expressa pela poesia pode ter acontecido. Como resultado dessa atividade, trago os desenhos a seguir:

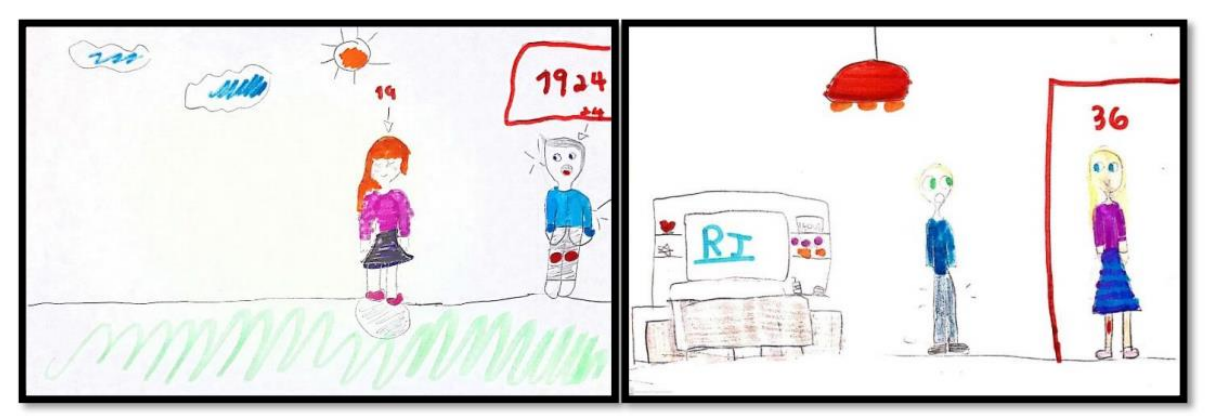

Fonte: Lima (2021) 
Mesmo que a atividade acima seja considerada apropriada para os alunos do quarto ano do Ensino Fundamental, acredito que ela possa ser estendida para alunos mais velhos e até mesmo mais proficientes na língua inglesa. Essa atividade possibilitou que os alunos expressassem suas interpretações através do estímulo à imaginação e criatividade, oferecendo-lhes formas diferentes e dinâmicas de estudar a língua norteadas pelo trabalho com a literatura. Em vista disso, entendo que o uso da poesia em sala de aula deve nutrir tanto o professor como o aluno com o entendimento de que a leitura de um texto literário não deve terminar no próprio texto; muitas outras questões merecem destaque. Questões essas que, conforme vimos anteriormente, estão além do texto e contribuem para aproximar o aluno da língua-alvo assim como possibilitar o exercício humanizador da literatura, especificamente, da poesia.

As atividades aqui discutidas correspondem apenas a uma gota no mar que representa as possibilidades de uso da poesia nas aulas de língua adicional. Cabe ao professor conhecer seus alunos e os contextos enfrentados, reconhecer a relevância da literatura no ensino e, assim, planejar atividades adequadas que possam contribuir com a aprendizagem significativa da língua-alvo. Não podemos desconsiderar também que, ao usar a poesia em sala de aula, o professor pode despertar o interesse dos alunos para a leitura de textos literários - o que seria um ganho expressivo para a educação e a sociedade.

\section{ÚLTIMAS CONSIDERAÇÕES?}

Ouso colocar um ponto de interrogação neste item de conclusão, visto que as discussões apresentadas neste ensaio são ainda incipientes. E esse fato pode ser reflexo, principalmente, da falta de material, pesquisas e relatos que envolvam o trabalho com a poesia nas aulas de língua inglesa, e também as demais línguas adicionais, nos contextos de ensino brasileiros. O que tenho percebido como professor e pesquisador da área é que pouco se tem falado quando o assunto é literatura, ensino e aprendizagem de língua inglesa; menor é a fala sobre o caráter humanizador da poesia em sala de aula. A literatura tem uma função social importante, todavia, é triste saber que essa função não é efetivamente reconhecida nas escolas. 
Assim, compreendo que, na tentativa de sanar essa lacuna e conscientizar (mesmo que a passos curtos e lentos) os principais atores do processo educacional, pesquisas devam ser elaboradas tendo a poesia e seu papel humanizador como focos. Cabe explicitar que não estou desfavorecendo o trabalho com aspectos linguísticos e estruturais da língua, pois entendo que trabalhar pontos gramaticais, por exemplo, em textos literários é também importante para a aprendizagem. Contudo, proponho que os professores não se atentem somente a esses aspectos. A poesia se apresenta como um tesouro pronto para ser descoberto e, ao considerarmos também sua relevância para a sociedade, assim como para os seres humanos, esse tesouro se expande, oferecendo aulas ricas, dinâmicas, lúdicas, interessantes e não centradas no professor. Afinal "poesia não é apenas beleza infensa à realidade; ela é beleza que torna para nós a realidade mais intensa" (PILATI, 2017, p. 47).

\section{Referências}

ANDRADE, Carlos Drummond de. Nova reunião: 23 livros de poesia. São Paulo: Companhia das Letras, 2015.

CANDIDO, Antonio. "O direito à literatura". In: CANDIDO, Antonio. Vários escritos. 5. ed. Rio de Janeiro: Ouro sobre Azul, 2011. p. 171-193.

ELIOT, T. S. De poesias e Poetas. Tradução de Ivan Junqueira. São Paulo: Brasiliense, 1991.

FRANCO, Bárbara Alves da Rocha. As multifacetas shakespearianas em sala de aula. CB TecLE, São Paulo, v. 1, n. 2, p. 30-46, jul./dez. 2017. Disponível em: https://revista.cbtecle.com.br/index.php/CBTecLE/article/view/58. Acesso em: 15 jul.2021.

LIMA, Leonardo Jovelino Almeida de. As poesias nas aulas de língua inglesa do Ensino Fundamental. In: CONELA, 1., 2020, Campina Grande. Anais... Aracaju: Ed. dos Autores, 2021. Disponível em: https://drive.google.com/file/d/1YRg5GxH9Tkb6_WEb0Hp15HvDRBkrhivc/view. Acesso em: 15 jul.2021.

MCCLOSKEY, Mary Lou; STACK, Lydia. Voices in Literature. Boston: Thompson Place, 1996.

MOISÉS, Carlos Felipe. Poesia para quê? A função social da poesia e do poeta. São Paulo: Editora Unesp, 2019. 
MOISÉS, Massaud. A criação literária: poesia e prosa. Ed. rev. e atual. São Paulo: Cultrix, 2012.

PAULA, Maria Ap. R. de. Diversidade e multiculturalismo por meio da literatura inglesa. Cadernos PDE, os desafios da escola pública paranaense na perspectiva do professor PDE, Curitiba, v. 1, 2016. Disponível em: http://www.diaadiaeducacao.pr.gov.br/portals/cadernospde/pdebusca/producoes_pde/20 16/2016_artigo_lem_uem_mariaaparecidaribeiro.pdf. Acesso em: 25 Jul.2021.

PAZ, Octavio. O arco e a lira. Tradução de Orga Savary. Rio de Janeiro: Nova Fronteira, 1982.

PILATI, Alexandre. Poesia na sala de aula: subsídios para pensar o lugar e a função da literatura em ambientes de ensino. Campinas: Pontes Editores, 2017.

PINHEIRO, Hélder. Poesia na sala de aula. São Paulo: Parábola, 2018.

SHELLEY, Percy Bysshe. Uma defesa da poesia e outros ensaios. Edição Bilíngue. São Paulo: Landmark, 2008.

SOUZA, Adriana Grade Fiori et al. Leitura em língua inglesa: uma abordagem instrumental. 2. ed. São Paulo: Disal, 2005.

TERRA, Ernani. Da leitura literária à produção de textos. São Paulo: Contexto, 2018.

TODOROV, Tzvetan. A literatura em perigo. Tradução de Caio Meira. Rio de Janeiro: DIFEL, 2009.

Recebido em: 31/08/2021

Aceito em: 02/01/2022

\footnotetext{
${ }^{1}$ Para maiores explicações sobre estratégias de leituras de textos em inglês, ver Souza et al. (2005).
} 